\title{
THE ANAEROBIC SPEED RESERVE OF HIGH-LEVEL SOCCER PLAYERS: A COMPARISON BASED ON THE RUNNING SPEED PROFILE AMONG AND WITHIN PLAYING POSITIONS
}

original paper

(c) University School of Physical Education in Wroclaw

DOI: https://doi.org/10.5114/hm.2018.81287

\author{
JAELSON GONCALVES ORTIZ ${ }^{1,2}$, ANDERSON SANTIAGO TEIXEIRA ${ }^{1}$, \\ PEDRO AUGUSTO MOHR ${ }^{1,2}$, PAULO CESAR DO NASCIMENTO SALVADOR ${ }^{1}$, \\ TIAGO CETOLIN $^{1,3}$, LUIZ GUILHERME ANTONACCI GUGLIELMO ${ }^{1}$, \\ RICARDO DANTAS DE LUCAS ${ }^{1}$ \\ ${ }^{1}$ Sports Center, Physical Effort Laboratory, Federal University of Santa Catarina, Florianópolis, Brazil \\ ${ }^{2}$ Avaí Futebol Clube, Florianópolis, Brazil \\ ${ }^{3}$ Figueirense Futebol Clube, Florianópolis, Brazil
}

\begin{abstract}
Purpose. The aim of the study was to examine the differences of the anaerobic speed reserve (ASR) in soccer players according to the playing positions (defenders, midfielders, and forwards).

Methods. Overall, 120 elite-level national Brazilian soccer players (46 defenders, 45 midfielders, and 29 forwards) performed a field incremental test to estimate maximal aerobic speed (MAS) and a 30-m sprint to determine maximal sprinting speed (MSS). The difference between MAS and MSS was used to estimate ASR. Players were classified by position and by MAS and MSS performance. For each playing position, they were ranked and divided into higher and lower MSS (MSS-H and MSS-L, respectively) and MAS (MAS-H and MAS-L, respectively) groups. The players' ASR was compared among these groups.

Results. The comparison of ASR within playing position showed no difference among defenders, midfielders, or forwards. In addition, a higher ASR was found for the fastest players (MSS-H) in all playing positions as compared with their MSS-L counterparts. When ASR was compared between MAS-H and MAS-L, a significant difference $(p<0.05)$ was observed. A high correlation was noted between ASR and MSS $(r=0.72 ; p<0.001)$ and between ASR and MAS $(r=-0.63 ; p<0.001)$. Conclusions. MSS is the main index that determines the magnitude of ASR, which should be considered when characterizing the soccer players' running speed profile. However, no difference was found when the playing positions were compared, indicating similar characteristics of the running profile in a large sample of soccer players.
\end{abstract}

Key words: aerobic assessment, metabolic profile, running speed, physical capacity

\section{Introduction}

The assessment of aerobic and anaerobic maximal speed in soccer players individually supports the running training [1], as well as provides a better comprehension of the differences in match performance among players [2]. In addition, the concept of anaerobic speed reserve (ASR), which represents the variation between the maximal aerobic and anaerobic power - i.e. maximal aerobic speed (MAS) and maximal sprinting speed
(MSS), respectively - could determine individual distinctions of fitness profiles within a soccer team.

Considering that ASR is an important measure capable to define tolerance during supramaximal-intensity exercise [1, 3, 4], it can be useful when comparing players of the same tactical function or between playing-position groups [5, 6]. Traditionally, the upper and lower boundaries of ASR have been considered for the analyses of soccer players' physical profile [7-9].

During the dynamics of a soccer match, players from

Correspondence address: Jaelson Gonçalves Ortiz, Sports Center, Physical Effort Laboratory, Federal University of Santa Catarina, Florianópolis - SC, Brazil, e-mail: ortiz_edfisica@yahoo.com.br

Received: October 30, 2018

Accepted for publication: January 5, 2019

Citation: Ortiz JG, Teixeira AS, Mohr PA, Do Nascimento Salvador PC, Cetolin T, Guglielmo LGA, De Lucas RD. The anaerobic speed reserve of high-level soccer players: a comparison based on the running speed profile among and within playing positions. Hum Mov. 2018;19(5)special/issue:65-72; doi: https://doi.org/10.5114/hm.2018.81287. 
J.G. Ortiz et al., Anaerobic speed reserve profile in soccer

different playing positions constantly interact with each other, e.g. defenders with the opposing forwards, midfielders with the opposing defenders, or forwards with the opposing midfielders [10, 11]. From this interaction, players with a similar technical status, but with higher ASR, regardless of the playing position, could have an advantage over an opponent with lower ASR and similar MAS [1, 4].

From a practical application perspective, Buchheit and Mendez-Villanueva [9] compared the magnitude of changes in the repeated-sprint performance in young soccer players during soccer matches in relation to changes in MSS and MAS between five successive seasons and showed that these results were dependent on the tactical function. On the other hand, the achievement of peak running speeds during soccer matches is positively related to MSS, regardless of the playing position, as demonstrated by Mendez-Villanueva et al. [4].

Beyond that, for a team with a similar technical level, it is preferable that players from all sectors of the field have a higher ASR, translating into a possible greater capacity to sustain the demands of supramaximal intensities related to the glycolytic system $[1,12]$. Thus, a team with players presenting higher capacity to sustain supramaximal intensities during a match could be advantageous, which one can consider as an alternative for analyses during the development of the fitness profile team, before and/or during the season, and for a specific match context [12, 13].

The comparative analysis of the running profile based on ASR and the physiological responses to supramaximal interval training from this magnitude should be observed carefully because some players present similar MSS, but different MAS could trigger discrepancies in the exercise tolerance during supramaximal intensities [1, 3, 9]. On the other hand, players may exhibit similar MAS but different MSS. Therefore, the higher the MSS, the better the 'running economy' will be at given supramaximal running speeds [14-16].

In a soccer match, the ability to perform sprints at higher speed thresholds, such as $31.0 \mathrm{~km} \cdot \mathrm{h}^{-1}$, could be determinant for certain playing positions and consequently allows for better recovery/economy when successive sprints are demanded at the highest speeds. In this context, Mendez-Villanueva et al. [4] compared the match performance between the fastest and the slowest players according to their positions (i.e. wide midfielders and central defenders). Indeed, the authors found that faster players reached higher peak running speeds during the matches in comparison with their slower counterparts, regardless of the playing position.
Accordingly, the aim of this study was to analyse soccer players' running profile on the basis of ASR and compare it among the playing positions, i.e. defenders, midfielders, and forwards. To the authors' knowledge, no studies have compared ASR among and within playing positions in high-level soccer players. The within-position comparisons were also made between groups with similar MSS or similar MAS.

\section{Material and methods}

\section{Participants}

The maximal aerobic and anaerobic running performances were collected from high-level male soccer players: 46 defenders, 45 midfielders, and 29 forwards (age: $20.9 \pm 3.3$ years; height: $1.76 \pm 6.4 \mathrm{~cm}$; body mass: $70.1 \pm 1.2 \mathrm{~kg}$; body fat percentage: 10.8 $\pm 1 \%$ ). The participants were recruited from two soccer teams which played in the first and second national division in Brazil. The individuals had been training and competing on a regular basis for a minimum of 5 years and were training $6-8$ hours per week, with one match every week during the season.

\section{Testing procedures}

\section{Maximal aerobic speed}

MAS was determined on the basis of the peak speed in the Carminatti's test (TCAR). It is an intermittent progressive field test with changes of direction of $180^{\circ}$, which allow the players to perform 5 repetitions of running in 12 seconds before the increase in speed at each stage (90 s), until exhaustion and voluntarily stopping the test [17]. The initial running speed of the TCAR is $9 \mathrm{~km} \cdot \mathrm{h}^{-1}$, with progressive increases of $1 \mathrm{~m}$ $\left(0.6 \mathrm{~km} \cdot \mathrm{h}^{-1}\right)$. The test was finished when the players failed to reach the return line audio cues in two consecutive repetitions in the required time. The TCAR peak speed was calculated in accordance with Kuipers et al. [7] for the athletes that could not complete the last stage.

\section{Maximal sprinting speed}

The subjects were assessed over a 30-m running sprint test with a split time in the first $10-\mathrm{m}$ distance. Each athlete repeated the sprint 3 times, and an at least 45-s passive rest was allowed. Thus, the best $20-\mathrm{m}$ (flying) time was used to determine the MSS. The 30-m sprint test was conducted outdoors, on a natural turf 
field, and the sprint time was recorded with a photocell system (CEFISE - Speed Test 6.0, São Paulo, Brazil). The participants started each sprint with the front foot placed $5 \mathrm{~cm}$ before the first timing gate and covered the distance in all-out running [18].

\section{Anaerobic speed reserve}

ASR was calculated as the difference between MSS and MAS, with the following equation

$$
\operatorname{ASR}\left(\mathrm{km} \cdot \mathrm{h}^{-1}\right)=\text { MSS }- \text { MAS [5]. }
$$

\section{Playing-position analysis}

For comparison purposes in descending order, i.e. from the fastest to the slowest players, all participants were divided into 3 groups: the fastest (or the first third group), the median third players (or the second group), and the slowest players (or the last third group). The median third was excluded from forming the groups of higher (MSS-H) and lower speed players (MSS-L) in order to compare the fastest and slowest players for each playing position. An identical process was applied for MAS analyses within each playing position (i.e. defenders, midfielders, and forwards). There was no overlapping in MSS or MAS values between the groups.

\section{Statistical analysis}

Descriptive statistics (mean $\pm S D$ ) were calculated for all the dependent variables (ASR, MSS, and MAS) and their distributions were confirmed as normal via the Shapiro-Wilk test. To compare the differences among the playing positions between MSS and MAS groups, a one-way analysis of variance was used for each dependent variable. In addition, a $t$-test was used within the groups to compare MSS-H vs. MSS-L and MAS-H vs. MAS-L. The level of statistical significance was set at $p<0.05$ for all analyses. The analy- ses were performed with the SPSS software (version 17.0) and the graphs were prepared with the GraphPad Prism (GraphPad Software).

\section{Ethical approval}

The research related to human use has been complied with all the relevant national regulations and institutional policies, has followed the tenets of the Declaration of Helsinki, and has been approved by the Federal University of Santa Catarina (university ethics committee approval number 2.047.140).

\section{Informed consent}

Informed consent has been obtained from all individuals included in this study and their legal guardians, after being advised, both verbally and in writing, of the risks and benefits involved in this study.

\section{Results}

The performance measurements for each test are presented in Table 1. All the grouped data presented no differences among the playing positions for the ASR, MAS, or MSS indices.

However, when the data were stratified (higher versus lower), significant differences were observed within playing positions and among playing positions (Table 2). The defenders' group with MSS-H presented ASR 17.4\% higher than their MSS-L counterparts $(p<0.019)$, while the group of midfielders with MSS-H showed ASR $13.4 \%$ higher than those with MSS-L $(p<0.001)$. The forwards' group with MSS-H showed ASR 17.4\% greater in comparison with their MSS-L counterparts $(p<$ $0.001)$. For the within-playing-position comparison, the MSS-H group showed higher values for MSS measurement in comparison with the MSS-L for all positions $(p<0.001)$. No significant differences were found for MAS in the within-playing-position analysis.

For the comparisons of ASR among the playing positions, the group of defenders with MSS-H showed no

Table 1. Descriptive data of the time performance in sprints and acceleration and the values of MSS, MAS, and ASR among positions

\begin{tabular}{lccr}
\hline Grouped data & Defenders $(n=46)$ & Midfielders $(n=45)$ & Forwards $(n=29)$ \\
\hline $30 \mathrm{~m}(\mathrm{~s})$ & $4.093 \pm 0.1$ & $4.090 \pm 0.3$ & $4.084 \pm 0.1$ \\
$20 \mathrm{~m}(\mathrm{~s})$ & $1.700 \pm 01$ & $1.775 \pm 0.4$ & $1.679 \pm 0.1$ \\
$10 \mathrm{~m}(\mathrm{~s})$ & $2.391 \pm 0.2$ & $2.422 \pm 0.1$ & $2.408 \pm 0.1$ \\
MSS $\left(\mathrm{km} \cdot \mathrm{h}^{-1}\right)$ & $30.1 \pm 1.1$ & $29.8 \pm 1.0$ & $29.9 \pm 1.1$ \\
MAS $\left(\mathrm{km} \cdot \mathrm{h}^{-1}\right)$ & $17.5 \pm 0.9$ & $17.4 \pm 0.9$ & $17.4 \pm 1.1$ \\
ASR $\left(\mathrm{km} \cdot \mathrm{h}^{-1}\right)$ & $12.7 \pm 1.4$ & $12.4 \pm 1.3$ & $12.6 \pm 1.5$ \\
\hline
\end{tabular}

MSS - maximal sprinting speed, MAS - maximal aerobic speed, ASR - anaerobic speed reserve 
J.G. Ortiz et al., Anaerobic speed reserve profile in soccer

differences in comparison with the midfielders (MSS-H); however, the group of defenders with MSS-H was 15.2\% higher than the group of midfielders with MSS-L ( $p<$ 0.001). No differences were found between defenders and forwards with MSS-H, but the defenders with MSS-H were $17.4 \%$ higher than forwards with MSS-L $(p=0.054)$. Moreover, a significantly greater value of $15.6 \%$ was observed for the midfielders' group with MSS-H in comparison with defenders with MSS-L. The same difference was found between midfielders with MSS-H and forwards with MSS-L $(p<0.001)$. Conversely, no dissimilarities were noted between midfielders and forwards with MSS-H.

Regarding the MSS, for the among-playing-position comparison, the group of defenders with MSS-H demonstrated a higher MSS in comparison with the midfielders and forwards with MSS-L (8.1\% and $7.7 \%$, respectively). Nevertheless, no differences were observed between the MSS-H defenders and MSS-H midfielders, or between MSS-H defenders and MSS$\mathrm{H}$ forwards. A significant difference between the MSS-H midfielders and MSS-L defenders (5.9\%) and between the MSS-H midfielders and MSS-L forwards $(6.2 \%)$ was found. On the other hand, no variances were noted between the midfielders and forwards with MSS-H. The MSS-H forwards showed a higher MSS in comparison with the defenders and midfielders with MSS-L (6.8\%, $p<0.001$ and 6.2\%, $p<0.001$, respectively). Finally, MAS presented no distinctions among the playing positions.

\section{MSS-H vs. MSS-L}

Figure 1A shows a significant difference between MSS-H vs. MSS-L groups for MSS ( $p=0.032)$ and ASR $(p<0.001)$, yet no difference was found for MAS.

\section{MAS-H vs. MAS-L}

Figure 1B displays a significant difference between MAS-H vs. MAS-L groups for MAS $(p<0.001)$ and ASR $(p<0.001)$, but no difference was found for MSS in both groups.

Figure 2A shows the relationships between ASR and MSS ( $r=0.72 ; p<0.0001)$, and Figure 2B demonstrates the relationships between ASR and MAS $(r=$ $-0.63 ; p<0.0001)$. There was no relationship between MAS and MSS $(r=0.07 ; p=0.406)$ (Figure 2C).

\section{Discussion}

The main purpose of the present study was to compare the magnitude of ASR between (and within) soccer playing positions among players who presented similar MAS and those who presented similar MSS. The findings allow to identify differences in the magnitude of ASR when comparing the faster and slower players, on the basis of their sprint speeds.

The primary findings of the present study in relation to ASR were that variations within each playing position and between the playing positions were only

Table 2. Within-playing-position and between-position differences considering the faster vs. slower players in MSS, MAS, and ASR and between-playing-position differences in MSS, MAS, and ASR

\begin{tabular}{|c|c|c|c|c|c|c|}
\hline \multirow[b]{2}{*}{ MSS reference } & \multicolumn{2}{|c|}{ Defenders } & \multicolumn{2}{|c|}{ Midfielders } & \multicolumn{2}{|c|}{ Forwards } \\
\hline & $\begin{array}{l}\text { MSS-H } \\
(n=18)\end{array}$ & $\begin{array}{l}\text { MSS-L } \\
(n=15)\end{array}$ & $\begin{array}{l}\text { MSS-H } \\
(n=17)\end{array}$ & $\begin{array}{l}\text { MSS-L } \\
(n=15)\end{array}$ & $\begin{array}{l}\text { MSS-H } \\
(n=12)\end{array}$ & $\begin{array}{l}\text { MSS-L } \\
(n=10)\end{array}$ \\
\hline $\operatorname{MSS}\left(\mathrm{km} \cdot \mathrm{h}^{-1}\right)$ & $31.2 \pm 0.4^{\mathrm{aA}}$ & $28.9 \pm 0.6$ & $30.7 \pm 0.5^{\mathrm{aA}}$ & $28.7 \pm 0.6$ & $30.8 \pm 0.6^{\mathrm{aA}}$ & $28.8 \pm 0.6$ \\
\hline $\operatorname{MAS}\left(\mathrm{km} \cdot \mathrm{h}^{-1}\right)$ & $17.3 \pm 0.8$ & $17.6 \pm 0.9$ & $17.2 \pm 0.9$ & $17.0 \pm 0.9$ & $17.0 \pm 0.9$ & $17.4 \pm 1.2$ \\
\hline $\operatorname{ASR}\left(\mathrm{km} \cdot \mathrm{h}^{-1}\right)$ & $13.8 \pm 0.8^{\mathrm{bA}}$ & $11.4 \pm 0.8$ & $13.5 \pm 1.0^{\mathrm{aAB}}$ & $11.7 \pm 1.1$ & $13.8 \pm 0.6^{\mathrm{Aa}}$ & $11.4 \pm 1.2^{\mathrm{A}}$ \\
\hline \multirow[b]{2}{*}{ MAS reference } & \multicolumn{2}{|c|}{ Defenders } & \multicolumn{2}{|c|}{ Midfielders } & \multicolumn{2}{|c|}{ Forwards } \\
\hline & $\begin{array}{l}\text { MAS-H } \\
(n=16)\end{array}$ & $\begin{array}{l}\text { MAS-L } \\
(n=17)\end{array}$ & $\begin{array}{l}\text { MAS-H } \\
(n=18)\end{array}$ & $\begin{array}{l}\text { MAS-L } \\
(n=15)\end{array}$ & $\begin{array}{l}\text { MAS-H } \\
(n=12)\end{array}$ & $\begin{array}{l}\text { MAS-L } \\
(n=10)\end{array}$ \\
\hline $\operatorname{MAS}\left(\mathrm{km} \cdot \mathrm{h}^{-1}\right)$ & $18.5 \pm 0.5^{\mathrm{a}}$ & $16.5 \pm 0.3$ & $18.3 \pm 0.5^{\mathrm{a}}$ & $16.5 \pm 0.4$ & $18.4 \pm 0.9^{\mathrm{a}}$ & $16.3 \pm 0.3$ \\
\hline $\operatorname{MSS}\left(\mathrm{km} \cdot \mathrm{h}^{-1}\right)$ & $30.3 \pm 1.0$ & $29.9 \pm 1.2$ & $30.0 \pm 0.9$ & $29.7 \pm 1.2$ & $30.2 \pm 0.6$ & $29.6 \pm 0.6$ \\
\hline $\operatorname{ASR}\left(\mathrm{km} \cdot \mathrm{h}^{-1}\right)$ & $11.9 \pm 1.1$ & $13.4 \pm 1.3$ & $11.7 \pm 1.1$ & $13.2 \pm 1.2$ & $11.8 \pm 0.6$ & $13.4 \pm 1.2$ \\
\hline
\end{tabular}

MSS - maximal sprinting speed, MAS - maximal aerobic speed, ASR - anaerobic speed reserve, MSS-H - higher MSS, MSS-L - lower MSS, MAS-H - higher MAS, MAS-L - lower MAS

Significant differences within positions: $\quad$ Significant differences among positions:

${ }^{\mathrm{a}} p<0.001$

${ }^{\mathrm{b}} p<0.05$

${ }_{\mathrm{A}}^{\mathrm{A}} p<0.05$
${ }^{\mathrm{B}} p<0.001$ 
A

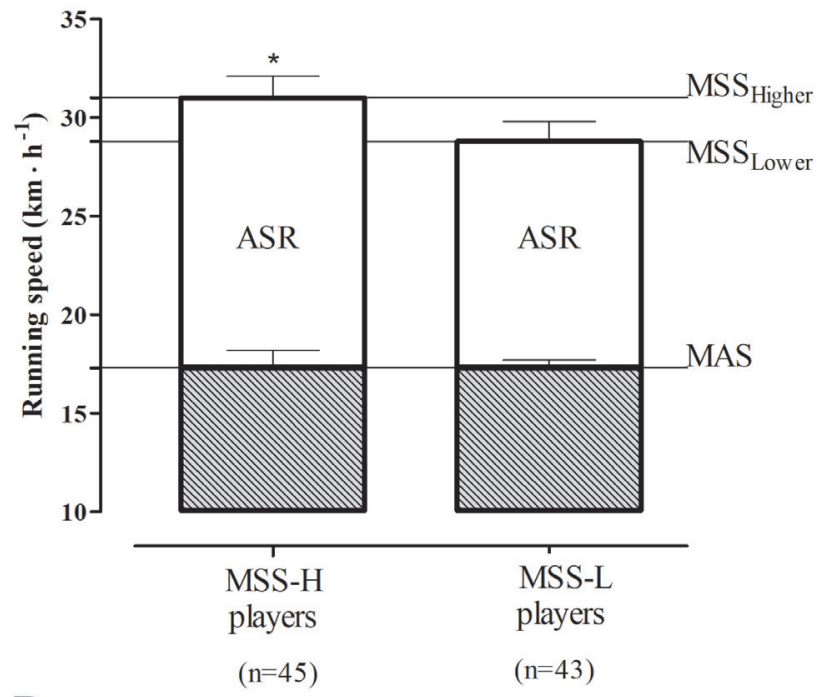

B

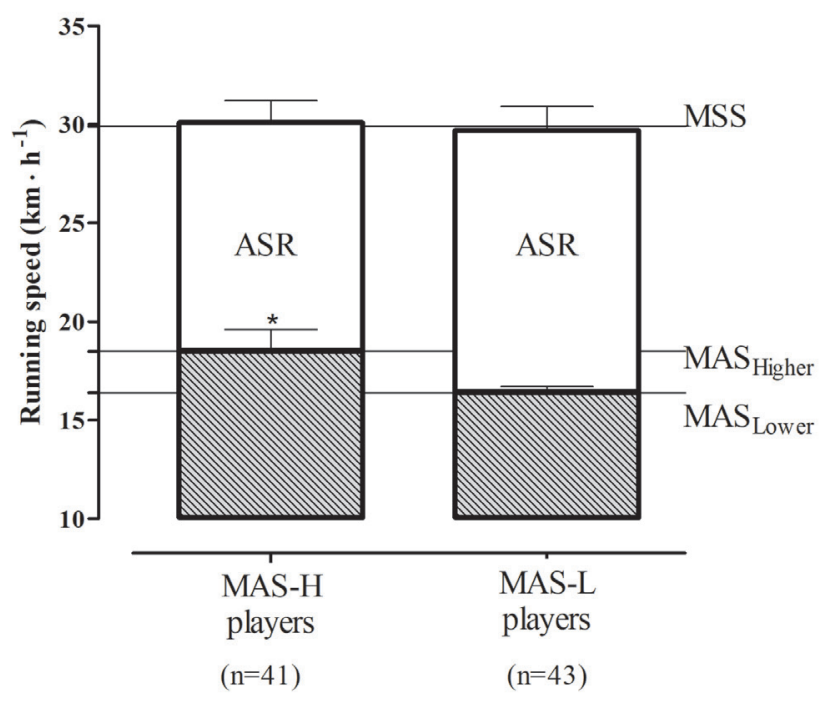

* significant difference between groups $(p<0.05)$

MSS - maximal sprinting speed, MAS - maximal aerobic speed,

ASR - anaerobic speed reserve, MSS-H - higher MSS,

MSS-L - lower MSS, MAS-H - higher MAS, MAS-L - lower MAS

Figure 1. Running speed profile (MAS and MSS) from faster and slower players. Panel A: Players with same MAS; B - Players with same MSS

observed when the reference was related to players with a similar MAS. Nonetheless, no differences were noted when similar MSS was set as a reference. To the best of the authors' knowledge, this is the first study to describe ASR in a large group of high-level soccer players.

Regardless of the playing positions, ASR was greater for the faster players' group (i.e. MSS-H) than for the slower ones. For instance, ASR values around 13.5$13.8 \mathrm{~km} \cdot \mathrm{h}^{-1}$ were observed for defenders, midfielders, and forwards with higher sprint speeds, while values around $11.4-11.7 \mathrm{~km} \cdot \mathrm{h}^{-1}$ were detected for their slower counterparts.
A

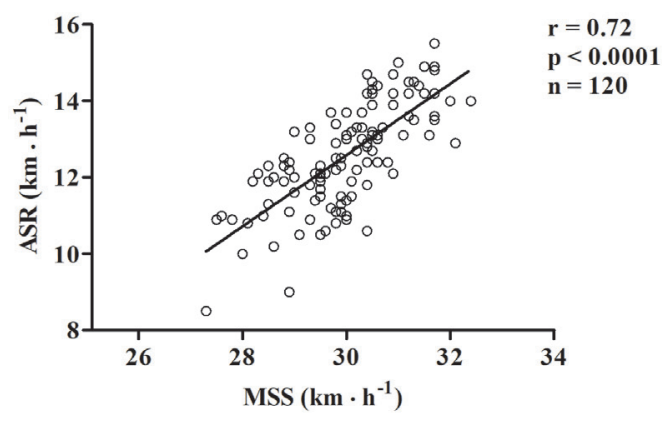

B
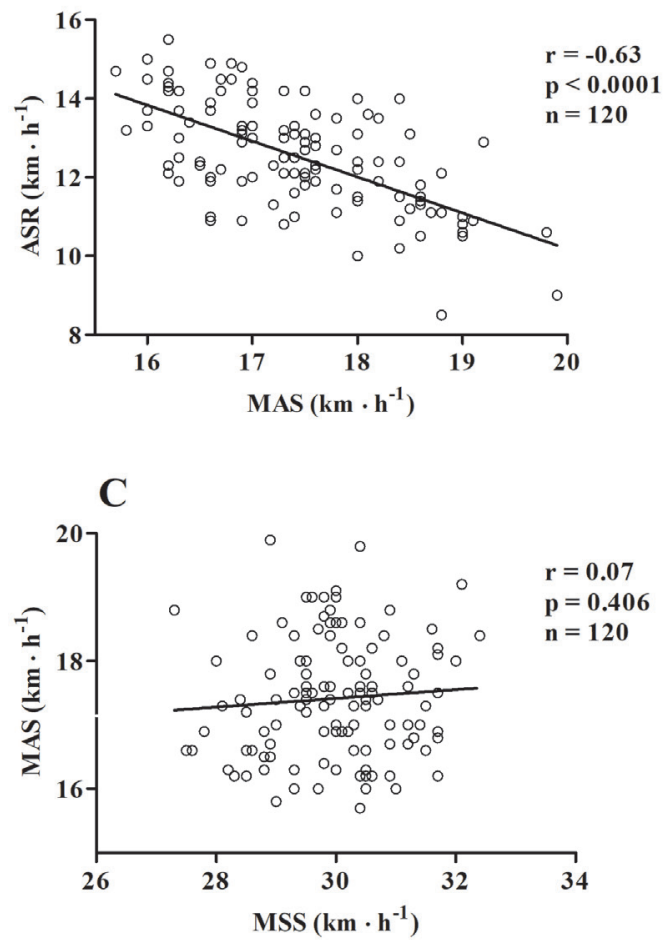

ASR - anaerobic speed reserve, MSS - maximal sprinting speed, MAS - maximal aerobic speed

Figure 2. Relationships between (A) ASR and MSS, (B) ASR and MAS. (C) MAS and MSS

The aim of stratifying players within the same playing position was to analyse if the upper and lower strata were the same among the positions. In the literature, forwards have proven to be faster than defenders or midfielders $[5,19,20]$. In the present study, forwards with MSS-H demonstrated no differences from defenders or midfielders with MSS-H. On the other hand, significant distinctions (ca. 6\%) were found among all the positions with MSS-H and MSS-L (Table 2).

From a practical perspective, ASR may be an important measure for player selection when considering a particular strategy for the team. When taking into 
J.G. Ortiz et al., Anaerobic speed reserve profile in soccer

account players with different running speed profiles (within the same playing position), those who exhibit better performances in supramaximal intensities are preferable for specific games or competitions. This practical application is in accordance with the comparisons among youth age categories demonstrated by Buchheit and Mendez-Villanueva [14] in highly trained soccer players. The authors assessed the supramaximal intermittent running performance in regard to the age and running profiles and showed that for a similar $\operatorname{MAS}\left(16.2 \mathrm{~km} \cdot \mathrm{h}^{-1}\right.$ and $16.7 \mathrm{~km} \cdot \mathrm{h}^{-1}$ for U-16 and U-18), a higher ASR (around $15 \mathrm{~km} \cdot \mathrm{h}^{-1}$ ) was found for U-18 compared with the U-16 athletes (around $13 \mathrm{~km} \cdot \mathrm{h}^{-1}$ ). In the same way, Mendez-Villanueva et al. [5] identified distinctions for ASR among several team categories, such as $10.9 \mathrm{~km} \cdot \mathrm{h}^{-1}$ in $\mathrm{U}-13,11.7 \mathrm{~km} \cdot \mathrm{h}^{-1}$ in $\mathrm{U}-14$, $12.9 \mathrm{~km} \cdot \mathrm{h}^{-1}$ in $\mathrm{U}-15,12.7 \mathrm{~km} \cdot \mathrm{h}^{-1}$ in $\mathrm{U}-16,14.3 \mathrm{~km} \cdot \mathrm{h}^{-1}$ in U-17, and $14.7 \mathrm{~km} \cdot \mathrm{h}^{-1}$ in U-18. Thus, it can be observed that there is a similarity with the current study values of the U-18 category, specifically owing to the similarity between MAS values.

Selmi et al. [21] demonstrated a great magnitude of ASR in 3 different contexts of the maturity status on the basis of peak height velocity (PHV). They found an ASR value of $16 \mathrm{~km} \cdot \mathrm{h}^{-1}$ for pre-PHV, $19 \mathrm{~km} \cdot \mathrm{h}^{-1}$ for intra-PHV, and $22 \mathrm{~km} \cdot \mathrm{h}^{-1}$ for post-PHV in U-14 soccer players. Probably because of the maturational status, which may influence the aerobic and anaerobic performances of young U-14 players, a higher ASR for the 3 maturation levels was observed in their study when compared with this study, which allowed for the magnitude of ASR among youngsters. This must be viewed with caution when comparing with adult athletes. In addition, MAS was evaluated by an incremental 20-m shuttle run test, which certainly underestimated the real MAS, thus inflating the ASR.

In this context, it is important to highlight that ASR is dependent on the way in which MAS and MSS are assessed [22]. Therefore, any comparison of ASR magnitude among studies might present some limitations. The peak speed of an incremental field test was used herein to assess MAS, which was demonstrated to detect the speed at $\mathrm{VO}_{2}$ max precisely $[17,23]$. On the other hand, a flying 20-m sprint speed was employed to set MSS. Many studies have used a flying 10-m sprint speed to define MSS [4, 14, 18]. Even if it could be considered a limitation, the present study compared a large sample of athletes using the same test setting.

Considering MSS, the current study detected the mean values of $30.1 \mathrm{~km} \cdot \mathrm{h}^{-1}$ for defenders, $29.8 \mathrm{~km} \cdot \mathrm{h}^{-1}$ for midfielders, and $29.9 \mathrm{~km} \cdot \mathrm{h}^{-1}$ for forwards, which is somewhat similar to other reports from the literature. Djaoui et al. [24] presented MSS values of $30.5 \mathrm{~km} \cdot \mathrm{h}^{-1}$ for central defenders, $31.0 \mathrm{~km} \cdot \mathrm{h}^{-1}$ for wide defenders, and $30.8 \mathrm{~km} \cdot \mathrm{h}^{-1}$ for central defenders. Mendez-Villanueva et al. [16] observed MSS values compatible with the above ones for wide defenders $\left(30.2 \mathrm{~km} \cdot \mathrm{h}^{-1}\right)$, but for all other positions, the results were higher: $35 \mathrm{~km} \cdot \mathrm{h}^{-1}$ for central defenders, $34.3 \mathrm{~km} \cdot \mathrm{h}^{-1}$ for wide midfielders, and $31.2 \mathrm{~km} \cdot \mathrm{h}^{-1}$ for central midfielders in elite youth soccer players. In amateur soccer players, Ferro et al. [25] showed higher values for MSS in relation to this study for all playing positions (ranging from 31.4 to $33 \mathrm{~km} \cdot \mathrm{h}^{-1}$ ). On the other hand, the present study revealed superior results for MSS in comparison with Al Haddad et al. [26], whose study, conducted among youth elite soccer players, demonstrated that defenders, midfielders, and forwards had a mean MSS near $28.7 \mathrm{~km} \cdot \mathrm{h}^{-1}$ and wide defenders and central defenders exhibited the mean value of $27.7 \mathrm{~km} \cdot \mathrm{h}^{-1}$. The MSS that represents the upper limit of ASR has been used as a reference for repeated sprints in a practical context, such as a match, and this variable allows for a better comprehension of the behaviour of the running profile in soccer athletes during training and competitions.

Regarding MAS, the results showed that when the whole dataset was grouped by playing position $\left(17.5 \pm 0.9 \mathrm{~km} \cdot \mathrm{h}^{-1}\right.$ for defenders, $17.4 \pm 0.9 \mathrm{~km} \cdot \mathrm{h}^{-1}$ for midfielders, and $17.4 \pm 1.1 \mathrm{~km} \cdot \mathrm{h}^{-1}$ for forwards), the values were in agreement with those reported by Fessi et al. [27] in professional male soccer players $\left(17.6 \pm 2.3 \mathrm{~km} \cdot \mathrm{h}^{-1}\right)$.

In addition, when the current study values were compared between players (within each position) with MAS-H (about $18.4 \mathrm{~km} \cdot \mathrm{h}^{-1}$ ) and MAS-L (about $16.5 \mathrm{~km} \cdot \mathrm{h}^{-1}$ ), the results presented similarities with a pre-post intermittent training period, as reported by da Silva et al. [23] in U-20 elite soccer players. This study found an improvement of MAS after 5 weeks of intermittent running training from 16.8 to $18.1 \mathrm{~km} \cdot \mathrm{h}^{-1}$ for the group that ran without changes of direction and from 16.6 to $17.5 \mathrm{~km} \cdot \mathrm{h}^{-1}$ for the group that performed a shuttle-run protocol. Supposedly, MAS could be more sensitive to improvement after a training period than MSS [26]. In this case, MAS-H could decrease the ASR magnitude if MSS was kept at the same level. The importance of a high aerobic fitness level for soccer players has been established by da Silva et al. [23] as an essential component which could allow the athletes to sustain the high demand of a competitive season.

The lack of available literature on this matter reveals the necessity for further transversal and longi- 
tudinal studies of ASR, in order to better understand how it could determine soccer match running performances.

Finally, monitoring ASR during a season is suggested in order to assist coaches in establishing parameters regarding the players' running speed profile, and potentially to aid the decisions about player selection for a given match or competition.

\section{Conclusions}

In conclusion, no differences in ASR were detected between playing positions in a large sample of soccer players. However, when the players were ranked and divided by their maximal aerobic and anaerobic speeds, significant differences were observed for all positions. In addition, the functional aerobic and anaerobic speeds indicate the importance of analysing running profiles in soccer players on the basis of ASR. Understanding the speed running profile of ASR could be relevant for increasing the competitive level of a team and improving the defensive and offensive technical vulnerabilities. Beyond that, these data provide a reference for other studies and coaches regarding the values of all playing positions, which present higher and lower ASR. Thus, this measure could be utilized for individual training prescription and tracking player profiles during a competitive season.

\section{Acknowledgements}

The authors would like to thank all the players and the Federal University of Santa Catarina for all support during the study development.

\section{Disclosure statement}

No author has any financial interest or received any financial benefit from this research.

\section{Conflict of interest}

The authors state no conflict of interest.

\section{References}

1. Buchheit M, Laursen PB. High-intensity interval training, solutions to the programming puzzle: Part I: cardiopulmonary emphasis. Sports Med. 2013;43(5):313338; doi: 10.1007/s40279-013-0029-x.

2. Bangsbo J. The physiology of soccer - with special reference to intense intermittent exercise. Acta Physiol Scand Suppl. 1994;619:1-155.

3. Blondel N, Berthoin S, Billat V, Lensel G. Relationship between run times to exhaustion at 90, 100, 120, and $140 \%$ of $\mathrm{vVO}_{2}$ max and velocity expressed relatively to critical velocity and maximal velocity. Int J Sports Med. 2001;22(1):27-33; doi: 10.1055/s-2001-11357.

4. Mendez-Villanueva A, Buchheit M, Simpson B, Peltola E, Bourdon P. Does on-field sprinting performance in young soccer players depend on how fast they can run or how fast they do run? J Strength Cond Res. 2011; 25(9):2634-2638; doi: 10.1519/JSC.0b013e318201c281.

5. Mendez-Villanueva A, Buchheit M, Simpson BM, Bourdon PC. Match play intensity distribution in youth soccer. Int J Sports Med. 2013;34(2):101-110; doi: 10.1055/s0032-1306323.

6. Schimpchen J, Skorski S, Nopp S, Meyer T. Are "classical" tests of repeated-sprint ability in football externally valid? A new approach to determine in-game sprinting behaviour in elite football players. J Sports Sci. 2016;34(6):519-526; doi: 10.1080/02640414.2015. 1112023.

7. Kuipers H, Verstappen FTJ, Keizer HA, Geurten P, van Kranenburg G. Variability of aerobic performance in the laboratory and its physiological correlates. Int J Sports Med. 1985;6(4):197-201; doi: 10.1055/s-20081025839.

8. Stølen T, Chamari K, Castagna C, Wisløff U. Physiology of soccer: an update. Sports Med. 2005;35(6):501536; doi: 10.2165/00007256-200535060-00004.

9. Buchheit M, Mendez-Villanueva A. Changes in repeatedsprint performance in relation to change in locomotor profile in highly-trained young soccer players. J Sports Sci. 2014;32(13):1309-1317; doi: 10.1080/02640414. 2014.918272.

10. Ric A, Torrents C, Gonçalves B, Torres-Ronda L, Sampaio J, Hristovski R. Dynamics of tactical behaviour in association football when manipulating players' space of interaction. PLoS One. 2017;12(7):e0180773; doi: 10.1371/journal.pone.0180773.

11. Gesbert V, Durny A, Hauw D. How do soccer players adjust their activity in team coordination? An enactive phenomenological analysis. Front Psychol. 2017;8:854; doi: 10.3389/fpsyg.2017.00854.

12. Polczyk M, Zatoń M. Effects of glycolytic-based interval training on anaerobic capacity in soccer players. Hum Mov. 2015;16(3):149-162; doi: 10.1515/humo2015-0041.

13. Dragula L, Lehnert M, Psotta R, Gonosová Z, Valenta S, Štastný P. The relative force in squat jump is the best laboratory predictor of sprint performance in adolescent soccer players. Hum Mov. 2017;18(5):83-90; doi: 10.5114/hm.2017.73622.

14. Buchheit M, Mendez-Villanueva A. Supramaximal intermittent running performance in relation to age and locomotor profile in highly-trained young soccer players. J Sports Sci. 2013;31(13):1402-1411; doi: 10.1080/ 02640414.2013 .792947$.

15. Bundle MW, Hoyt RW, Weyand PG. High-speed running performance: a new approach to assessment and prediction. J Appl Physiol. 2003;95(5):1955-1962; doi: 10.1152/japplphysiol.00921.2002. 


\section{HUMAN MOVEMENT}

J.G. Ortiz et al., Anaerobic speed reserve profile in soccer

16. Mendez-Villanueva A, Hamer P, Bishop D. Fatigue in repeated-sprint exercise is related to muscle power factors and reduced neuromuscular activity. Eur J Appl Physiol. 2008;103(4):411-419; doi: 10.1007/s00421008-0723-9.

17. Dittrich N, da Silva JF, Castagna C, de Lucas RD, Guglielmo LGA. Validity of Carminatti's test to determine physiological indices of aerobic power and capacity in soccer and futsal players. J Strength Cond Res. 2011; 25(11):3099-3106; doi:10.1519/JSC.0b013e3182132ce7.

18. Loturco I, Pereira LA, Kobal R, Maldonado T, Piazzi AF, Bottino A, et al. Improving sprint performance in soccer: effectiveness of jump squat and Olympic push press exercises. PLoS One. 2016;11(4):e0153958; doi: 10.1371/ journal.pone.0153958.

19. Sporis G, Jukic I, Ostojic SM, Milanovic D. Fitness profiling in soccer: physical and physiologic characteristics of elite players. J Strength Cond Res. 2009;23(7):19471953; doi: 10.1519/JSC.0b013e3181b3e141.

20. Boone J, Vaeyens R, Steyaert A, Vanden Bossche L, Bourgois J. Physical fitness of elite Belgian soccer players by player position. J Strength Cond Res. 2012;26(8): 2051-2057; doi: 10.1519/JSC.0b013e318239f84f.

21. Selmi MA, Al-Haddabi B, Yahmed MH, Sassi RH. Does maturity status affect the relationship between anaerobic speed reserve and multiple sprints sets performance in young soccer players? J Strength Cond Res. 2017; doi: 10.1519/JSC.0000000000002266.

22. Boullosa DA. The forgotten pieces of the high-intensity interval training puzzle. Sports Med. 2014;44(8):11691170; doi: 10.1007/s40279-014-0188-4.

23. Da Silva JF, Nakamura FY, Carminatti LJ, Dittrich N, Cetolin T, Guglielmo LGA. The effect of two generic aerobic interval training methods on laboratory and field test performance in soccer players. J Strength Cond Res. 2015;29(6):1666-1672; doi: 10.1519/ JSC.0000000000000776.

24. Djaoui L, Chamari K, Owen AL, Dellal A. Maximal sprinting speed of elite soccer players during training and matches. J Strength Cond Res. 2017;31(6):15091517; doi: 10.1519/JSC.0000000000001642.

25. Ferro A, Villacieros J, Floría P, Graupera JL. Analysis of speed performance in soccer by a playing position and a sports level using a laser system. J Hum Kinet. 2014;44:143-153; doi: 10.2478/hukin-2014-0120.

26. Al Haddad H, Simpson BM, Buchheit M, Di Salvo V, Mendez-Villanueva A. Peak match speed and maximal sprinting speed in young soccer players: effect of age and playing position. Int J Sports Physiol Perform. 2015;10(7):888-896; doi: 10.1123/ijspp.2014-0539.

27. Fessi MS, Farhat F, Dellal A, Malone JJ, Moalla W. Straight-line and change-of-direction intermittent running in professional soccer players. Int J Sports Physiol Perform. 2018;13(5):562-567; doi: 10.1123/ ijspp.2016-0318. 